\title{
CHAPTER
}

\section{The Senior Living Field: Background, History, and Its Current and Future State}

\section{INTRODUCTION}

The field of aging services has evolved tremendously over the years. In 1657, the first almshouses were built in New York (Abramovitz, 1996). Almshouses originally created by the Dutch were also called poor houses or county homes in the United States, which were locally administered public institutions for homeless, aged persons without means. These facilities were often created as extensions of churches or other charitable organizations. The leaders of these settings were typically referred to as wardens or superintendents. More often, during these early years, care and service of elders was still largely dependent on family support.

From the late 17th century until the early 20th century, the so-called poor houses provided by churches or other organizations were the state of elder care facilities in the United States until the government started to play a more significant role during the period of the Great Depression. One of the first notable actions was the passing of the Social Security Act of 1935. Title I of the act forged a partnership between the federal government and states to address, to some degree, the financial challenges of the older population. Additionally, a key element of the Act had both employers and employees make contributions for a supplemental workers' retirement fund. Initially, this social safety net was set at the age of 65 , which was based on the life expectancy in the United States at the time (Centers for Disease Control and Prevention [CDC], 2017). Both elements helped provide some modest level of support to elders in their later years.

One of the next significant legislative initiatives was the passing of the HillBurton Act in 1946. Although the new law focused on hospital growth, it did serve as a model for some long-term care (LTC) funding. The funding for senior care during this period was largely contributed by nonprofit groups, such as religious-affiliated organizations, and was very limited in scope. There was somewhat of a boom of LTC building growth following the Hill-Burton Act in the 1950s, mostly by for-profit housing and real estate with Federal Housing Authority and Small Business Administration loans being used to finance these projects. One of the characteristics of the funding arrangements that was notable was the significantly financially leveraged funding models that were used by these groups. Due 
to the limited experience in the provision of care and services for elders, this period of LTC history could be described as one with abundant variation and with little quality control or oversight.

President Lyndon Johnson's efforts in 1965 for comprehensive reform of senior living services launched a much larger role of government in senior care. The Older Americans Act (OAA) was signed into law with many broad aims, including:

- focus on ensuring adequate retirement incomes;

- consideration of both physical and mental health;

- provision of suitable housing;

- good restorative services;

- the pursuit of meaningful activity;

- community services, including access to low-cost transportation;

- supporting demonstration projects and research; and

- enabling individual initiative in planning and managing their own lives.

The driver of these services was mostly through the Administration on Aging (AOA) via matching grants to qualifying states, ranging from community-based planning, demonstration grants, research on aging, and personnel training, to creating recreational facilities and guidance centers. However, funding services for the aging was limited because of other priorities in the country at the time, such as the war in Vietnam (Administration for Community Living, 2019).

The Long-Term Care Ombudsman Program was also authorized under the OAA and administered at the state level. It provides residents of LTC facilities with access to effective advocacy in order to ensure that they receive the quality of care and quality of life they deserve and are entitled to by law.

The year 1965 also saw the passage of Medicare and Medicaid. Medicare was advanced as a health insurance program for the elderly. Medicaid was put into place as a health insurance program for low-income persons in the United States. Both were established as part of the Social Security Act. They embodied a major policy shift for the country in face of greater life expectancy and needed senior services and continue to stand the test of time. Several senior care services, most notably skilled nursing care (or, at the time, nursing home care) and home care, saw tremendous growth and availability for individuals after enaction of the law.

In addition to the growth of senior living services and medical coverage, there was also legislation bringing housing reform with the passage of the Housing and Urban Development Act of 1965. The legislation expanded funding for existing federal housing programs and added new programs that provided rent subsidies for the elderly and disabled; housing rehabilitation grants to poor homeowners; provisions for veterans to make very low down payments to obtain mortgages; new authority for families qualifying for public housing to be placed in empty private housing (along with subsidies to landlords); and matching grants to localities for the construction of water and sewer facilities, construction of community centers in low-income areas, and urban beautification. The Department of Housing and Urban Development (HUD) was also created. In many instances, HUD paved the way for affordable senior housing and LTC facilities' growth across the country, especially in high population urban areas, in the 1960s through the 1980s. 
As LTC facilities grew in number, there was a greater call for national standards of quality. The Federal Nursing Home Reform Act, passed in 1987 (also known as OBRA'87), created a set of national minimum set of standards of care and rights for people living in certified nursing facilities. This landmark federal legislation came at a time when many were calling for enhanced quality and service in the nursing home field due to public concerns about some poor living conditions placing frail elders at risk. This legislation had a significant impact on rules and regulations over the next couple of decades.

The American With Disabilities Act (ADA) became law shortly after OBRA in 1990. The ADA, a civil rights law, prohibited discrimination against individuals with disabilities in all areas of public life. The purpose of the law was to make sure that people with disabilities had the same rights and opportunities as everyone else. The ADA gave civil rights protections to individuals with disabilities similar to those provided to individuals on the basis of race, color, sex, national origin, age, and religion. It has guaranteed equal opportunity for individuals with disabilities and is divided into five different sections that relate to different areas of public life (ADA, 2019). As a matter of general knowledge, the ADA applies to all citizens, but LTC facility residents are disproportionately disabled-so they benefit from the protections included in the law.

In the past few decades, there have been several other sections added to shore up legislation and provide more options and better standards to the LTC field.

- In 1997, the Balanced Budget Act was a bipartisan legislation that was an effort to curb Medicare payments. It also launched the creation of Medicare Part C (Medicare Advantage). The legislation also allowed states to advance state Medicaid managed care organization (MCO) programs. It also made enhancements to the State Children's Health Insurance Program (SCHIP) and was initially funded by an increased tobacco tax.

- In 2003, the Medicare Modernization Act (MMA) was passed and created Medicare Part D (prescription drugs), which began in 2006. This law allows individuals to voluntarily enroll in private plans that are approved by the Centers for Medicare \& Medicaid Services (CMS) and has helped mitigate the challenges of prescription drug costs for seniors (Kellogg Foundation, 2019).

- Home- and community-based services (HCBS) became even more readily available in 1983, when Congress added section 1915(c) to the Social Security Act, giving states the option to receive a waiver of Medicaid rules governing institutional care. In 2005, HCBS became a formal Medicaid state plan option. Several states include HCBS in their Medicaid state plans. Forty-seven states and DC are operating at least one 1915(c) waiver.

- The Older Americans Act Reauthorization Act of 2016 was passed and signed into law by President Obama. The Act helps older adults age with independence and dignity in their homes and communities and protect elders in LTC facilities and other settings. Reauthorization strengthens and improves this program's effectiveness. It clarifies both organizational and individual conflicts of interest within the program; improves resident access to ombudsmen; better protects the confidentiality of ombudsman information; ensures that state ombudsmen receive ongoing training; and permits ombudsmen, when feasible, to continue to serve residents transitioning from an LTC facility to a home care setting. 


\section{THE PATIENT PROTECTION AND AFFORDABLE CARE ACT}

The Patient Protection and Affordable Care Act (ACA) was signed into law in 2010 and has three main objectives:

1. To reform the private insurance market-especially for individuals and smallgroup purchasers-and make affordable health insurance available to more people. The law provides consumers with subsidies ("premium tax credits") that lower costs for households with incomes between $100 \%$ and $400 \%$ of the federal poverty level.

2. To expand Medicaid to the working poor with income up to $133 \%$ of the federal poverty level and expand the Medicaid program to cover all adults with income below 138\% of the federal poverty level. (Not all states have expanded their Medicaid programs.)

3. To change the way that medical decisions are made by supporting innovative medical care delivery methods designed to lower the costs of healthcare generally (Healthcare.gov, 2019).

There are also numerous policy advances happening today that are focused on value-based care and services and incentivizing and rewarding efforts to work across the silos of services and settings, including improvements for Medicare Advantage plans and advancing Medicare payment and delivery reforms with accountable care organizations. A few of the other enhancements within the ACA for seniors included providing prescription drug discounts, adding more preventive visits eligibility, and a focus on fraud and abuse within Medicare (see Exhibit 1.1 for more information).

\section{EXHIBIT 1.1 Highlights of the Legislative Initiatives in Senior Care}

1935 Social Security Act passed to provide Old Age Assistance and Survivors Insurance.

1946 Hill-Burton Act passed to give hospitals and other health facilities grants and loans for construction and modernization.

1959 Housing Act established Section 202: Supportive Housing for the Elderly as part of the Housing and Urban Development (HUD) program.

1965 Older Americans Act established the Administration on Aging, and Medicare and Medicaid were added to the Social Security Act.

1973 Older Americans Act Comprehensive Services Amendments established Area Agencies on Aging. The amendments added grants for multipurpose senior centers.

1974 Title XX of the Social Security Amendments authorized grants to states for social services.

1975-1981 Older Americans Act amendments authorized coverage of a variety of services for seniors, grants to Indian Tribal Organizations, Congregate Housing Service, and required states to establish a long-term care ombudsman program to cover nursing homes.

1983 Congress added Section 1915(c) to the Social Security Act, allowing homeand community-based services to be more readily available.

1987 Omnibus Budget Reconciliation Act provides for nursing home reform. 1990 Americans with Disabilities Act extended protection to persons with disabilities. 
also allowed states to advance state Medicaid managed care organization (MCO) programs.

2003 Medicare Prescription Drug, Improvement, and Modernization Act enactment, which included the creation of Medicare Part D, a prescription drug benefit, and Medicare Advantage Plans.

2005 Home- and Community-Based Services became a formal Medicaid state plan option based on Section 1915.

2010 The Affordable Care Act was put into place by executive order.

* There have been ongoing amendments to the Older Americans Act focusing on additional protections and expansion of services, particularly in the home- and community-based service arenas with state implementation emphasized.

\section{THE CURRENT STATE AND FUTURE OUTLOOK OF LONG- TERM CARE AND SENIOR SERVICES}

Since the Social Security Act of 1935 became law, America has continued to steadily expand the capacity of, elevate the standards for, devote more resources to, and heighten its expectations for senior living care and services. With the senior population expected to grow tremendously in the decades to come and with new preferences emerging for services, there are many opportunities and challenges for the field and for future LTC leaders and administrators. Significant influences on them include various demographic trends, developments in each line of service, and growth in population segments that require specific care and service needs.

\section{Demographic Trends}

By 2050, the population of individuals who are 65 and older in the United States is projected to double, growing faster than any other age group. As seniors age, their risk of having chronic diseases or functional limitations increases. According to LeadingAge, a national association that represents non-profit aging service providers, these risks are higher among members of minority groups, who are expected to make up $42 \%$ of the senior population in 2050 (LeadingAge, 2019). The risk of having a functional limitation or chronic disease is also higher among those living in poverty, who were 16\% of the senior population in 2010 but whose numbers are expected to grow in the future. Many seniors, however, wish to remain in their homes and communities for as long as possible. This presents new challenges for America's senior living field because of its current reliance on institution-based care and the changing demographics of the available workforce (see Exhibit 1.2).

\section{Present-Day Providers and Services}

The postacute network of lines of services and settings is robust and ever changing based on the demand and preferences of this aging population. There are some who would say that these lines of service are blurring a bit, yet they do each still have their own distinct set of principles and philosophies of care and service.

Long-term acute care hospitals (LTACHs) are facilities that specialize in the treatment of patients with serious medical conditions that require care on an ongoing basis but no longer require intensive care or extensive diagnostic procedures. A LTACH needs to be designed to deliver more complex clinical care than a skilled 


\section{EXHIBIT 1.2 Projected Population of Older Adults by 2035}

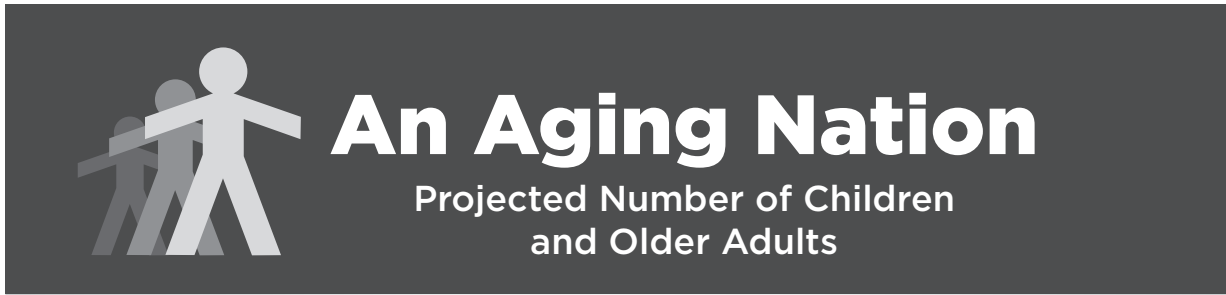

For the First Time in U.S. History Older Adults Are Projected to Outnumber Children by 2034

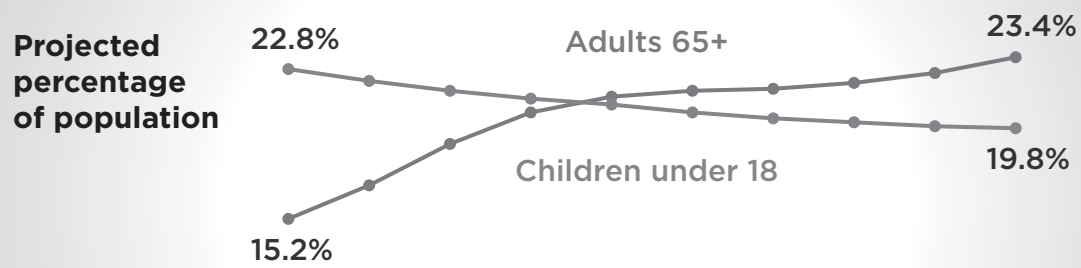

Projected number

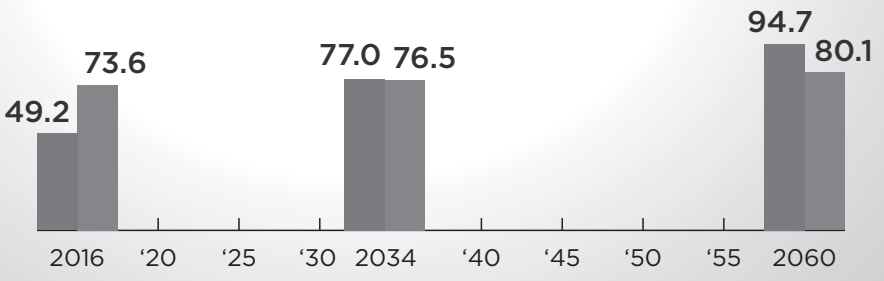

(millions)

Note: 2016 data are estimates not projections.

United States ${ }^{\circ}$ ensus Bureau
U.S. Department of Commerce U.S. CENSUS BUREAU

census.gov
Source: National Population Projections, 2017 www.census.gov/programs-surveys /popproj.htm

Source: U.S. Census Bureau. (2018). An aging nation: Projected number of children and older adults. Retrieved from https://www.census.gov/library/visualizations/2018/comm/historic -first.html

nursing facility (SNF), because LTACH residents are in poorer health and less able to care for themselves. Current estimates are that the country has approximately 400 of these operating in the United States.

SNF is an inpatient rehabilitation center staffed with trained medical professionals. Such facilities provide the medically necessary services of nurses, physical and occupational therapists, speech pathologists, and audiologists. There are approximately 15,000 SNFs in the United States. These facilities are still referred to as nursing homes, yet most have moved well past that era. It is true that some residents are still receiving traditional services for a long-term stay; however, many more have shifted their services to much more rehabilitation and specialized services.

Assisted living facility is housing for elderly or disabled people and provides some level of nursing care, housekeeping, social activities, and prepared meals as needed and based on individual preferences. There are more than 28,000 assisted living residences in the United States, housing more than 1 million people, according 
to the National Center for Assisted Living (NCAL). The "typical" assisted living resident is an 83-year-old woman, and the average age of all assisted living residents is 83 . The average female/male ratio in assisted living residences is 3:1. According to the NCAL, the average size of an assisted living residence is 43 units and ranges from 3 units to 200 units. The average number of residents in a facility is 40 , with a range of 1 to 175. Residential care is also provided by many states through their Medicaid program with waiver programs and provides a similar level of service than assisted living. Assisted living generally falls into a couple of categories, including either a social model or a medical model. One of the distinct recent areas of development in the more medically oriented sites are facilities that specialize in memory care.

The low-income HUD and its supportive housing for the elderly program is an important presence in the field. HUD's Section 202 program helped expand the supply of affordable housing with supportive services for the elderly. It provided direct loans and capital advances from the federal government to support nonprofit entities to build housing for very low-income elderly. Senior housing through Section 202 provided seniors, defined as 62 or older, with options that allow them to live independently but in an environment that provides support activities such as cleaning, cooking, transportation, and others. Although funding has was tightened in 2012, affordable senior housing developments that were built with Section 202 funds continue to provide housing and services to their residents. There are new programs from the Federal Housing Authority that have helped supplement the capital needs of senior housing in recent years.

Independent senior housing in the private market continues to be a viable option for many seniors who explore this option earlier than some of the others. These senior housing properties for those 55-plus years in age often focus on being safe and affordable with convenient amenities. There continues to be tremendous growth in this arena with some recent attention to the middle-income market population (Pearson et al., 2019).

Continuing care retirement communities (CCRC) and life plan communities are retirement communities that include the span of services that offer a continuum of care, including independent living, assisted living, skilled nursing, and home care options. Elderly persons can spend the rest of their life and "age in place" without moving from the community. These settings often require a deposit or an investment as part of entrance fee along with their monthly fees structure.

Group or family care homes are housing settings that include services where seniors or people with disabilities live in the same building; these are sometimes called group homes and are usually smaller in size and often cater to certain populations. For individuals with intellectual and developmental disabilities, a group care home is sometimes an option, although these individuals may also prefer support with home care with their families.

\section{Home- and Community-Based Services}

Home health is a range of healthcare services that can be received in the home for an illness or injury. Home health care can be less expensive and more convenient and may be just as effective as care received in another setting. There were approximately 12,200 agencies in the United States in 2016 (CDC, 2019).

Homecare or personal care is also offered in a variety of ways across the country, including covered services for nonmedical or custodial care services. Homemaker services are also available for assistance with general household chores that an 
individual is not able to do at their residence. These services are generally covered under Medicaid depending on the state the person lives in and their waiver program.

Hospice offers four levels of care, two of which happen at home. The four levels are as follows:

- Routine Home Care: This is the most common level of hospice care, and this includes nursing and home health aide services.

- Continuous Home Care: This is provided when a person needs continuous nursing care during a time of crisis or emergency.

- General Inpatient Care: This is short-term care during times when pain and symptoms cannot be managed without a hospital setting.

- Respite Care: This is short-term care in a facility during times when the patient's caregiver needs a break in caregiving.

Hospice care differs from palliative care, which serves anyone who is seriously ill, not just those who are dying and no longer seeking a cure (National Hospice and Palliative Care Association, 2018).

Adult day centers provide social and some home health services for seniors. The typical services include social activities, transportation, meals and snacks, personal care, and therapeutic activities. There are approximately 4,600 adult day centers in the United States (National Adult Day Association, 2019).

Multipurpose senior centers serve a wide range of needs both in terms of services and as a connection for other community services. These sites have a variety of funding sources, including a relationship with the OAA with nearly 10,000 centers across the country (National Council on Aging, 2019).

The new Health Service Executive model of licensure for leaders in senior care allows individuals to practice in the broader continuum of senior care services. This model focuses on a critical set of core knowledge and skills required to lead organizations and takes into consideration the ever-changing field of care and service options available to the elders of our country.

Randy Snyder, Executive Director, Minnesota Board of Executives for Long-Term Services and

Supports

\section{SPECIAL TARGET POPULATIONS}

Memory care is provided in a variety of settings. The most common form is an assisted living-type facility with enhanced safety and security features and generally more staff. The average cost of memory care is about $\$ 5,000$ a month, but such facilities provide care for those with Alzheimer's or other dementias, with 24-hour supervised care for patients at all stages of the disease (Howley, 2019). There are also 
options in SNFs with special units designed or adapted for this population. Many individuals also use home health services, especially in the early stages.

Intellectual and developmental disabilities often occur at childhood and are chronic issues that can be cognitive or physical, or even both. For those with developmental disabilities, there may also be related physical issues, as is the case for patients with cerebral palsy. People may also have both physical and cognitive issues in addition to intellectual disability, as is the case with Down syndrome. These populations depend on both Medicare and Medicaid, along with charitable or private resources from the family or caregivers. Typical services and settings vary as much as the individual situation and can include housing, education and employment coordination, and healthcare services.

\section{Older Inmates and Parolees}

"Of the 2.3 million adults in state and federal prisons, about 246,000 are 50 or older, according to the National Institute of Corrections. The United States currently spends more than $\$ 16$ billion annually caring for these aging inmates, and their numbers are projected to grow dramatically in the next 15 years" (Vestal, 2014). Under the 1965 law that created Medicaid, anybody entering a state prison forfeited Medicaid eligibility. An exception to that general rule was created in 1997 when the U.S. Department of Health and Human Services informed states that inmates who leave state or local facilities for care in hospitals or nursing homes can get their bills paid by Medicaid. The federal contribution varies by state for those individuals requiring services. Even in states that have not expanded Medicaid to low-income adults under the ACA, most elderly or disabled prison inmates qualify under existing Medicaid rules if they receive care outside the correctional facility.

\section{LGBTQ Older Population}

There are an estimated 3 million LGBTQ seniors over the age of 65 years, and this number is projected to double by 2030. Two common care-related issues are as follows: (a) They have fewer children to support them, and (b) they have discrimination issues that are not protected by federal civil rights laws (National Resource Center for LGBT, 2019). The hope is that the conversation in LTC and senior living facilities about the challenges of discrimination is becoming more frequent and that strides have been gained during the past 10 years with a more public discourse. It is imperative that leaders and administrators are sensitive to the diverse needs of the deserving LGBTQ senior citizens entrusted to our care and service.

\section{Ethnicity and Race}

The numbers and corresponding proportions of older people of diverse racial and ethnic origins in the United States are increasing. In 1990, ethnic minorities represented $13 \%$ of the population age 65 and older-a percentage that rose to $16 \%$ in 2000 and is projected to increase to $23 \%$ by 2020 and to $36 \%$ by 2050 . This increase is projected based on higher birth rates and the immigration numbers among racial 
and ethnic minority populations. There are several issues about the demographic factors that will impact the care and the delivery of LTC services across all lines of service. Among people over 70 who require care, Whites are most likely to receive help from their spouses, Latinx are most likely to receive help from their children, and African Americans are the most likely to receive help from a nonfamily member (National Academy on an Aging Society, 2000). These likelihoods often impact the types of LTC services a person receives and who provides them.

\section{Immigrant Groups}

As of 2017, immigrants accounted for more than $18 \%$ of healthcare workers. In nursing homes, nearly one in four workers who directly care for patients are immigrants, as are nearly one in three housekeeping and maintenance workers (Zallman, Finnegan, Himmelstein, Touw, \& Woolhandler, 2019). For immigrants who need service, good information is not readily available; however, it is generally believed that they pay for their own care with private funds out of fear and risk of deportation.

\section{Specific Medical Conditions}

For many individuals with disease-specific issues, they are likely to select staying at home for as long as they can until care stressors or depletion of financial resources occurs. Patients with greater service needs, such as with multiple sclerosis (MS), for example, which is one of the most common conditions found in skilled nursing care residents, often require some form of residential care. Approximately $20 \%$ to $25 \%$ of people with MS require some form of HCBS, and another 5\% will need residential LTC and often skilled nursing care due to financial funding models. Amyotrophic lateral sclerosis (ALS) is another example of a condition that requires individuals to navigate the use of support and care resources. Often as ALS progresses and financial resources are depleted, a decision is made about the use of home care resources or placement in a residential care setting as the person and family navigate what might be the better option (ALS Association, 2020).

\section{Pediatric LTC}

One last service line available in the country is pediatric LTCFs, which are defined as LTC, subacute, or rehabilitation facilities. These specialty care settings serve a population of children who have medically complex needs. There are a growing number of patients who require this service. The special care needs of these children are met by the estimated 40 providers across the country who fill this critical niche for these children and their parents (Pediatric Complex Care Association, 2016).

\section{FUTURE FACTORS AFFECTING LONG-TERM CARE AND SENIOR LIVING FACILITIES}

So the elephant in the room is clear to most people associated with this field. One of the most significant demographic trends in the United States is that America is graying (see Exhibit 1.3). This presents opportunities and challenges in the years ahead. 


\section{EXHIBIT 1.3 Population Changes (by Age) in 1960 Versus 2060}

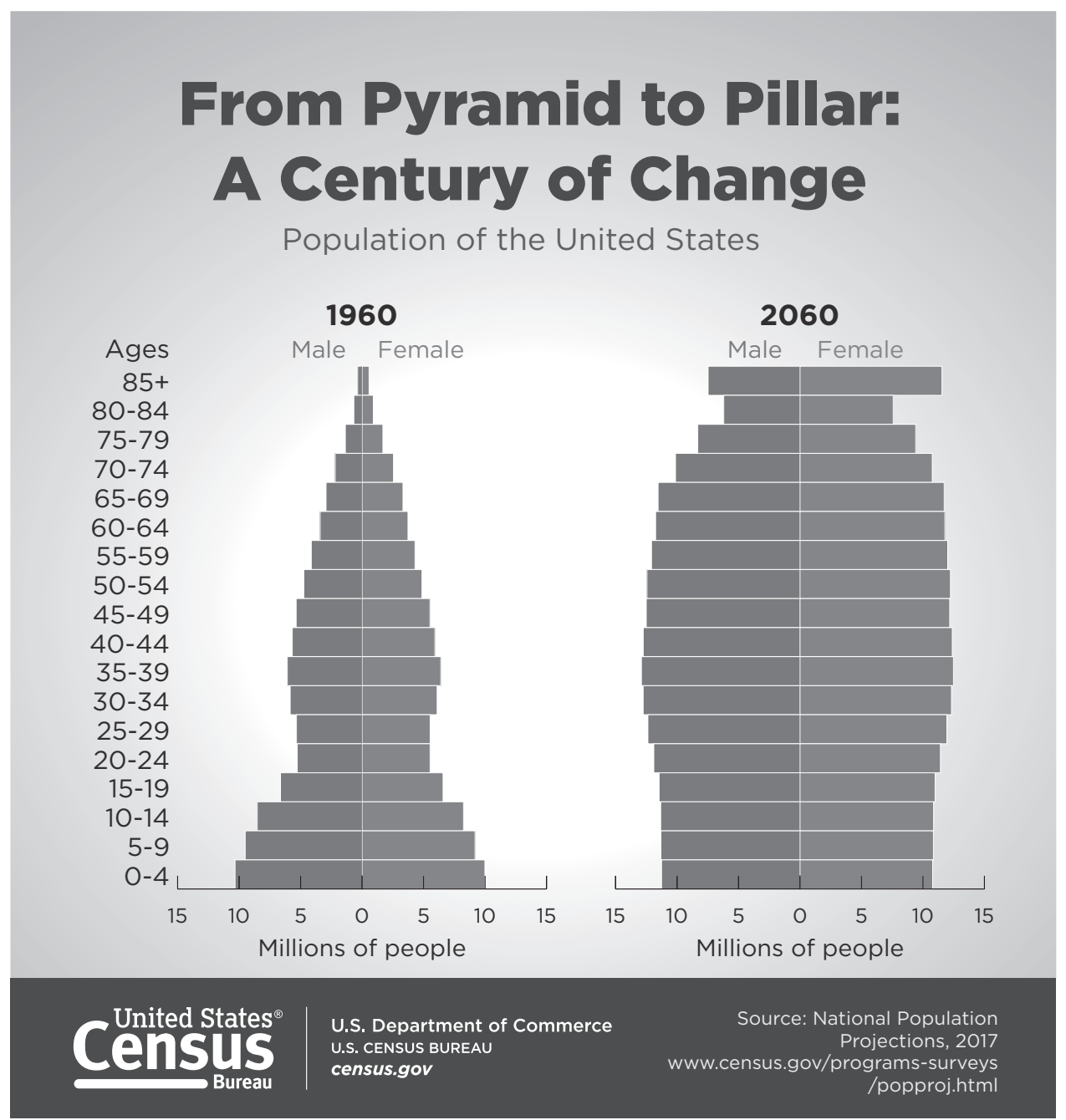

Source: U.S. Census Bureau. (2018). From pyramid to pillar: A century of change, population of the U.S. Retrieved from https://www.census.gov/library/visualizations/2018/comm/century -of-change.html

Based on this huge shift in our population, as well as the changing landscape of public policy and consumer perspectives, there are a few noteworthy issues that require greater awareness for leaders and administrators in the senior living field:

- Consumer expectations of the baby boomers who want good senior care and high-quality services, often in different environments and venues than their parents' generation

- The intersection of customer satisfaction and hospitality models of care and service that are challenging us to reexamine our approach to healthcare services for seniors

- Rising consumer awareness around quality and value that is further heightened with transparency of publicly available quality data 
- A variety of workforce development and supply issues, such as addressing the needs and wants of the new millennial workforce or responding to government immigrant policies

- Value-based purchasing being deployed by healthcare organizations and systems with required outcome accountability

- Rural and urban trends with technology driving some of the care and service approaches

- The expanding senior care continuum driving new and more meaningful relationships with both clinics and acute care hospitals

These topics and others will be explored throughout this text in a variety of ways. Determining the future landscape of the field is within the grasp of every individual leader involved and involves adaptation in both micro- and macro-ways.

Steven Chies, an executive who has been deeply entrenched in the development of senior care leaders within the provider, association, and academic worlds, shared some views of aging policy, trends, and the future needs of the profession.

The societal and financial impact of the baby boomer cohort on the United States economy will be felt at multiple levels. This impact will require senior care leaders who are able to meet the complexity of care needs for boomers, the challenging financial issues, and the expectations for control over their living and care settings.

Firstly, with the aging boomer cohort now into their 70 s and moving into retirement, having succession plans for senior care organizations should be a key part of their strategic planning. The ability to transfer knowledge from the experiences of boomers who have worked in the "longevity economy" will be of considerable benefit to the organizations as they transition leaders going forward.

Secondly, the boomers will no longer be in the higher tax-paying segment of society but will be using governmental funding resources, including Social Security, Medicare, and probably Medicaid, for their care needs. This will cause serious public policy discussions on the needs versus demands of the boomer cohort to meet their care needs and living expectations.

Thirdly, as the early boomers hit the magical age of 80 in 2026, an age that will peak in the 2032-2033 years, the need for chronic care settings, rehabilitation, and other care requirements will expand to fill the demands.

Finally, current and future senior care leaders will need to expand and broaden their knowledge and skills to avoid becoming narrowly focused in their career decisions. As the National Association of Long Term Care Administrator Boards (NAB) has demonstrated and 
predicted the need for a broader educational curriculum with their Health Services Executive (HSE ${ }^{T M}$ ) model, a number of current senior care leaders are seeking to go beyond the care and institutional settings and adopt a more expansive array of skills to lead the future of the sector.

The textbook has been written to provide the starting point for both current and prospective senior care leaders who are charged with leading senior living organizations into the "new normal." The HSE ${ }^{T M}$ credential will allow individuals and organizations to view careers in the "longevity economy" as having expanded options and leadership opportunities across all lines of service and at a national level.

Predicting exactly what the future care and living settings for the boomer cohort is very difficult as consumer expectations and the ability of the aging population to self-fund financial needs will be a key challenge for society. One can look at the demographics and data for each cohort in the United States and see what the growth of a senior care population will be, but how to create, staff, and fund the future for boomers is a challenge for the Health Services Executives going forward.

Steven Chies, Program Director, St. Joseph's College of Maine

\section{SUMMARY}

It is important for the emerging leader to have some context for the landscape of aging services in this country. Understanding the history and development of the field adds depth of perspective to future leaders. A view of the broadening of the landscape of senior services also sets a framework for how this continued evolution of service may evolve to meet both the necessary and desired services delivered and desired by future elders. The changing and diverse populations expected in the decades ahead will also be a key driver that leaders will want to pay attention to as the health and service system responds to these population shifts.

\section{KEY POINTS}

1. The history of aging services is a long-standing tradition in society that even predates the United States.

2. Legislative changes are important to understand as is their impact on delivery of services and funding.

3. Providers and services have evolved across the continuum over the years based on needs in the U.S. population.

4. Populations served are diverse and complex with different needs and LTC preferences. 
5. Leaders must understand the continuum so they can effectively practice today and position themselves strategically for future changes and challenges.

6. Aging trends should be paid attention to help predict future needs.

\section{LEADERSHIP ROLES}

1. Leaders need to be historians.

2. Leaders are responsible for understanding how policy impacts delivery.

3. Leaders need to understand the changing landscape that impacts their services, financials, strategies, personnel decisions, and facilities.

\section{QUESTIONS FOR DISCUSSION}

1. Describe the key policy and legislative shifts that influenced senior care delivery.

2. What are some of the unintended consequences of policy changes that have happened over the years?

3. What are some of the major impacts of the baby boomer generation on different lines of service available both today and in the future?

\section{CASE PROBLEM}

Consider a specific county in the United States that an individual would like to practice in and explore both the demographic footprint and the current provider availability for the provision of services. You will need to do the research using both public and private databases to get a robust picture of the landscape and the potential opportunities for service needs and supply.

\section{REFERENCES}

Abramovitz, M. (1996). Regulating the lives of women: Social welfare policy from colonial times to the present. Boston, MA: South End Press.

Administration for Community Living. (2019). Older Americans Act. Retrieved from https: / / acl .gov/about-acl / authorizing-statutes / older-americans-act

ALS Association. (2020). Paying for home care. Retrieved from http: / / www.alsa.org/als-care / resources / fyi / paying-for-home-care.html

Americans with Disabilities Act. (2019). An overview of the Americans With Disabilities Act. Retrieved from https: / / adata.org/ factsheet/ ADA-overview

Centers for Disease Control and Prevention. (2017). United States Life Tables, 2013. National Vital Statistics Reports, 66(3), 1-63. Retrieved from https: / / www.cdc.gov/nchs/data/nvsr/ nvsr66/nvsr66_03.pdf

Centers for Disease Control and Prevention. (2019). Home health care. Retrieved from https: / / www.cdc.gov/nchs / fastats / home-health-care.htm

Healthcare.gov. (2019). Affordable Care Act (ACA). Retrieved from https: / www.healthcare.gov / glossary / affordable-care-act/

Howley, E. (2019). Dementia care in assisted living homes. U.S. News. Retrieved from https:// health.usnews.com/ best-assisted-living / articles / dementia-care-in-assisted-living-homes 
Kellogg Foundation. (2019). An overview of the Medicare part D prescription drug benefit. Retrieved from https: / / www.kff.org/medicare/ fact-sheet/ an-overview-of-the-medicare-part-d -prescription-drug-benefit/

LeadingAge. (2019). Why housing plus services. Retrieved from https: / / www.leadingage.org/ why-housing-plus-services

National Academy on an Aging Society. (2000). Chronic and disabling conditions: Caregiving. Washington, DC: The Gerontological Society of America.

National Adult Day Association. (2019). Overview and facts. Retrieved from https: / www.nadsa .org/consumers / overview-and-facts /

National Council on Aging. (2019). Senior center facts. Retrieved from https: / / www.ncoa.org/ news / resources-for-reporters / get-the-facts / senior-center-facts /

National Hospice and Palliative Care Association. (2018). NHPCO facts and figures. Retrieved from https: / / www.nhpco.org/wp-content/uploads / 2019/07/2018_NHPCO_Facts _Figures.pdf

National Resource Center for LGBT. (2019). Retrieved from https:/ / www.lgbtagingcenter.org/

Pearson, C., Quinn, C., Loganathan, S., Datta, A., Mace., \& Grabowski, D. (2019). The forgotten middle: Many middle-income seniors will have insufficient resources for housing and health care. Health Affairs, 38(5). doi:10.1377 / hlthaff.2018.05233

Pediatric Complex Care Association. (2016). 2015 clinical pilot benchmark study. Retrieved from https: / pediatriccomplexcare.org/wp-content/ uploads / 2016/04/PCCA-2015ClinicalBen chmarkPilotExecSum041116LM.pdf

Vestal, C. (2014). For aging inmates, care outside prison walls. Pew Stateline. Retrieved from https:/ / www.pewtrusts.org/en/research-and-analysis/blogs/stateline/2014/08/12 / for -aging-inmates-care-outside-prison-walls

Zallman, L., Finnegan, K., Himmelstein, D., Touw, S., \& Woolhandler, S. (2019). Care for America's elderly and disabled people relies on immigrant labor. Health Affairs, 38(6). doi:10.1377/hlthaff.2018.05514

\section{ADDITIONAL RESOURCES}

Achenbaum, W. A., \& Carr, L. C. (2014). A brief history of aging services. Generations, Summer 2014. Centers for Medicare \& Medicaid Services. (2019). History. Retrieved from https:/ / www.cms .gov/ About-CMS / Agency-Information/History

Department of Housing and Urban Development. (2019). Section 202 supportive housing for the elderly program. Retrieved from https: / / www.hud.gov / program_offices/housing/mfh/ progdesc/eld202

Khan, A., Tavakoli, N., \& Stefanacci, G. (2017). Management of medical complications in a longterm care patient with multiple sclerosis. Annals of Long-Term Care: Clinical Care and Aging, 25(2), 44-47.

Medicaid.gov. (2019). Home and community based services authorities. Retrieved from https:/ / www.medicaid.gov/medicaid/home-community-based-services/home-community -based-services-authorities/index.html

Pandya, S. (2005). Racial and ethnic differences among older adults in long-term care service use. AARP Public Policy Institute. Retrieved from https:/ / www.aarp.org/home-garden/livable -communities/info-2005/fs119_ltc.html

Pew Charitable Trusts and MacArthur Foundation. (2014). State prison health care spending. Retrieved from https:/ / www.pewtrusts.org/ /media/Assets/2014/07/StatePrison HealthCareSpendingReport.pdf

U.S. Senate Special Committee on Aging. (2019). The nursing home reform act turns twenty: What has been accomplished, and what challenges remain. Retrieved from https: / / www.aging.senate .gov/ hearings/the-nursing-home-reform-act-turns-twenty-what-has-been-accomplished -and-what-challenges-remain 